Adrian F. Fernando, MD Antonio H. Chua, MD',2

Lily L. Sia-Vargas, MD'

'Department of Otorhinolaryngology Head and Neck Surgery

University of the East - Ramon Magsaysay

Memorial Medical Center, Inc.

Quezon City, Philippines

${ }^{2}$ Department of Otorhinolaryngology

Head and Neck Surgery

Jose R. Reyes Memorial Medical Center

Manila, Philippines

Correspondence: Adrian F. Fernando, MD

Department of Otorhinolaryngology - Head \& Neck Surgery

Rm. 463, Hospital Service Bldg., UERMMMC, Inc,

64 Aurora Blvd., Quezon City, Philippines 1113

Telephone: +632-7150861 local 257

Telefax: +632-7161789

E-mail: ianfernando_md@yahoo.com

Reprints will not be available from the authors.

The authors declared that this represents original material that is not being considered for publication or has not been published or accepted for publication elsewhere, in full or in part, in print or electronic media; that the manuscript has been read and approved by all the authors, that the requirements for authorship have been met by each author, and that each author believes that the manuscript represents honest work.

Disclosures: The authors signed disclosures that there are no financial or other (including personal) relationships, intellectual passion, political or religious beliefs, and institutional affiliations that might lead to a conflict of interest.

Presented at the Case Report Poster Presentation, Philippine Society of Otolaryngology Head and Neck Surgery Mid-Year Convention, Taal Vista Hotel, Tagaytay City, April 22-24, 2010.

\title{
Nodular Fasciitis in a One-Year-Old Male: A Diagnostic Dilemma
}

\begin{abstract}
Objectives: To present a rare case of nodular fasciitis presenting as a supra-auricular mass.
\end{abstract}

\section{Methods:}

\author{
Design: Case Report \\ Setting: Private Tertiary University Hospital \\ Patient: One
}

Results: A one-year-old boy presented with an initially painless, left supra-auricular mass that rapidly enlarged from $<1 \mathrm{~cm}$ to $3 \mathrm{~cm}$ (widest diameter) in a two-month period. Sarcoma was initially considered over an inflammatory process as the mass was non-responsive to antibiotic therapy. Fine-Needle Aspiration Cytology (FNAC) and High-Resolution Computed Tomography (HRCT) with contrast revealed benign cytologic and radiologic findings making nodular fasciitis the primary impression.

The patient eventually underwent complete surgical excision of the left supra-auricular mass. Histopathologic findings then showed a stroma rich in collagen and myxoid ground substance and loose array of short S-shaped fascicle cells with scattered lymphocytes, macrophages and red blood cells consistent with nodular fasciitis.

Conclusion: Nodular fasciitis is a rare benign myofibroblastic soft tissue tumor which typically presents as a rapidly progressive nodular lesion in the head and neck region of the young pediatric age group. Cytopathologic recognition with FNA is a challenge. The gold standard of treatment is still surgical and in most reported cases, curative. More importantly, early clinical recognition and correlation with radiologic and histopathologic appearance is very important to avoid unnecessary work-ups and over-treatment.

Keywords: Nodular fasciitis; pseudosarcomatous fasciits; aggressive fibromatosis, desmoid tumor

Nodular fasciitis is a benign myofibroblastic proliferation in soft tissue that is frequently misdiagnosed as a sarcoma. It is also known as pseudosarcomatous fasciitis and subcutaneous pseudosarcomatous fibromatosis. Most patients are middle aged and the upper extremity is the most common localization. It is rarely diagnosed in childhood but appears in the head and neck region more commonly in children than in adults.' Nodular fasciitis remains a difficult diagnosis, particularly when it occurs in the head and neck as it may mimic other benign conditions and aggressive malignant neoplasms (Table 1). ${ }^{2}$ Nodular fasciitis could be rare, under-reported or simply misdiagnosed and not reported at all. A case of nodular fasciitis involving the supraauricular area of a one-year-old male child is presented emphasizing early clinical and pathological recognition to avoid misdiagnosis and over-treatment. 


\section{CASE REPORTS}

Table 1. Differential diagnosis for a rapidly expanding nodular lesion on the head and neck Adapted from: Rosenberg A. Bones, Joints and Soft Tissue Tumors. In: Cotran R, Kumar V, Collins T. editors. Robbins Pathologic Basis of Disease, 6th ed. Philadelphia: W. B. Saunders Co.1999. p. 1259 - 1267.

\begin{tabular}{l|c}
\multicolumn{1}{c|}{ Benign lesions } & Malignant Lesions \\
\hline Benign fibrous histiocytoma & Sarcomas: Pleomorphic sarcomas \\
\hline Pleomorphic lipoma & Liposarcoma \\
\hline Fibroxanthoma & Osteosarcoma \\
\hline Schwannoma & Leiomyosarcoma \\
\hline Neurofibroma & Rhabdomyosarcoma \\
\hline Proliferative fasciitis / myositis & Myxofibrosarcoma \\
\hline Ischaemic fasciitis & Spindle Cell Carcinoma \\
\hline Pleomorphic hyalinizing angiectatic tumor & Spindle Cell Melanoma \\
\hline Giant cell tumor & Spindle Cell Myoepithelioma or Carcinoma \\
\hline Hemangioma & \\
\hline Symplasmic glomus tumor & \\
\hline Nodular fasciitis & \\
\hline
\end{tabular}

Table 2. Auricular Nodular Fasciitis: Mean Size and Duration of Symptoms by Location (Source: Thompson LD, Fanburg-Smith JC, Wenig BM. Nodular fasciitis of the external ear region: a clinicopathologic study of 50 cases. Ann Diagn Pathol. 2001 Aug; 5(4):191-198.)

\begin{tabular}{l|c|c|c|}
\multicolumn{1}{c|}{ Anatomic Site } & Number & Size (cm) & $\begin{array}{c}\text { Durations of Symptoms } \\
\text { Prior to Recognition (mos.) }\end{array}$ \\
\hline Ear, not otherwise specified & 5 & 2.0 & 2.2. \\
\hline External auditory canal & 6 & 1.3 & 1.6 \\
\hline Pinna & 2 & 2.3 & 4.0 \\
\hline Pre-auricular & 18 & 1.8 & 4.4 \\
\hline Post-auricular & 19 & 2.1 & 7.7 \\
\hline TOTAL & $\mathbf{5 0}$ & $\mathbf{1 . 9}$ & $\mathbf{5}$ \\
\hline
\end{tabular}

\section{CASE REPORT}

A one-year-old male presented with a two-month history of a rapidly enlarging, painless, left supra-auricular mass. The mass was mobile, non-compressible and tender to deep palpation. There was no history of trauma nor response to analgesic and antibiotic treatment. A month after, the patient was seen at our out-patient clinic with a $3 \mathrm{~cm}$ tender and tense nodular transilluminating supraauricular mass, pushing the auricular triangular fossa laterally (Figure 1). Fine Needle Aspiration Cytology (FNAC) of the mass was done to rule out an overlying malignancy, specifically a sarcoma. Microscopic examination showed cellular smears with inflammatory cells on a hemorrhagic background (Figure 2). With nodular fasciitis as the primary consideration, contrast-enhanced High Resolution Computed Tomography (HRCT) was requested to delineate the extent of the mass and rule out possible infiltration and extension to adjacent structures, particularly intracranial. The HRCT showed a $2.8 \mathrm{~cm}$ well demarcated soft tissue density nodule in the left supra-auricular region with a well delineated fat plane separating the mass from the temporalis muscle and no evident involvement of underlying bone and adjacent soft tissue. The external auditory canal, middle and inner ear structures as well as the tegmen tympani and posterior sinus end plates were normal and the HRCT was read as a first branchial cleft cyst vs. soft tissue hemangioma (Figure 3).

The left supra-auricular mass was excised under general anesthesia and intra-operative findings showed a $2.5 \mathrm{~cm}$ well-circumscribed unencapsulated nodular mass at the left supra-auricular area overlying the temporalis muscle and laterally displacing the superior auricle. There was no muscular or other soft tissue infiltration of surrounding structures. The patient was discharged on the third post-operative day.

Grossly, the mass was $2.3 \mathrm{~cm}$ on its widest diameter, nodular, circumscribed and unencapsulated, surrounded by fat tissues. The specimen showed a loose array of short S-shaped fascicle cells accompanied by a small number of scattered lymphocytes, macrophages, and red blood cells indicating an inflammatory process with possible micro-hemorrhages. The stroma was rich in collagen and myxoid ground substance and an accelerated mitotic index with normal mitoses all consistent with nodular fasciitis (Figure 4). No recurrence was evident on three follow-up consultations for the past seven months.

\section{DISCUSSION}

Nodular fasciitis, first described in 1955 by Konwaler et al. ${ }^{3}$ is a benign, reactive proliferation of fibroblasts in the subcutaneous tissues which is commonly associated with the deep fascia. It is also known as pseudosarcomatous fibromatosis because of the marked cellular atypia and mitotic activity that are usually present or proliferative fasciitis when "ganglion-like" cells are present. ${ }^{3,4}$ It generally presents as a solitary painless, rapidly growing nodule, commonly arising in the upper extremities (flexor surface of the forearm) and the trunk (chest wall and back) of adults and in the head and neck region of infants. ${ }^{1,4}$ It may also involve vascular and cranial structures with the intravascular type mostly occurring before the age of 30 and the cranial type occurring in infants under 2 years of age. ${ }^{5}$ There is no sex predilection for nodular fasciitis or intravascular fasciitis, but cranial fasciitis is more frequent in boys. ${ }^{6}$ The etiology of nodular fasciitis is still unknown though some patients report trauma to the site of the lesion prior to the occurrence of the tumor. One theory on its pathogenesis is due to an unusual proliferation of myofibroblasts triggered by local injury or an inflammatory process. ${ }^{3}$ The cytomorphology of nodular fasciitis is fairly characteristic, making it possible to recognize these lesions in 


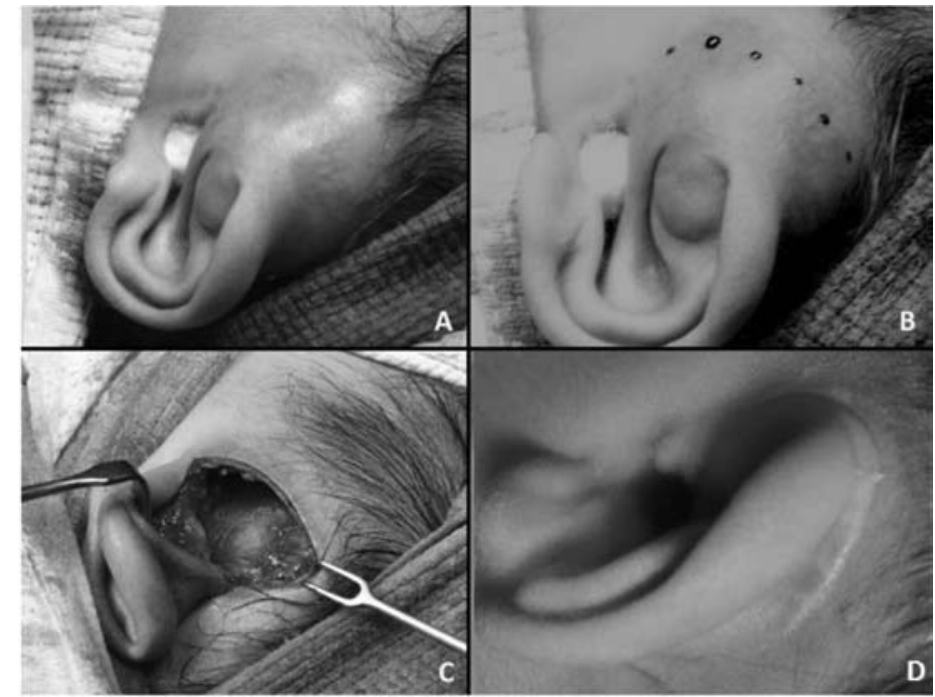

Figure 1. 1-year old male with a rapidly enlarging nodular left supra-auricular mass of 2 monthsduration.

1.A Nodular mass, approximately $2.8-3 \mathrm{~cm}$ in widest diameter, non-compressible and mobile under subcutaneous tissue, disfiguring the auricular triangular fossa as it pushes the superior auricular structures postero-laterally.

1.B Supra-auricular incision skin marking

1.C Intraoperative view after complete excision of mass. Note intact temporalis fascia and muscle.

1.D Healed incision site, 1 month post excision.

fine needle aspirates with an experienced pathologist. Due to lack of clear-cut clinical features, correct clinical diagnosis of nodular fasciitis requires a high index of suspicion and correlation of both FNAC and radiologic findings. ${ }^{7,8}$

Grossly, nodular fasciitis may appear circumscribed or infiltrative but is not encapsulated. ${ }^{9}$ The cut surface varies from myxoid to fibrous, and occasionally there is central cystic change. Microscopically, it is composed of plump but regular spindle-shaped fibroblasts or myofibroblasts lacking nuclear hyperchromasia and pleomorphism. Mitotic figures may be abundant, but atypical mitoses are not expected. ${ }^{10}$ The lesion may be highly cellular, but typically it is at least partly loose appearing and myxoid. In more cellular areas, there is often growth in S- or C-shaped fascicles and sometimes a storiform pattern. ${ }^{3}$ There is normally little collagen with some isolated cases composed of extensive stromal hyalinization. Extravasated red blood cells, chronic inflammatory cells and multinucleated osteoclast-like giant cells are other frequently identified features.?

Nodular fasciitis typically grows rapidly and has a preoperative duration of not more than 1-2 months while the longest known duration is 26 months. ${ }^{8}$ Soreness or tenderness may be present when the mass is enlarged enough to distend or compress adjacent structures. It usually measures $2 \mathrm{~cm}$ or less and almost always is less than $5 \mathrm{~cm}$. HRCT imaging of nodular fasciitis typically reveals a smoothly marginated soft-tissue mass that may or may not enhance with contrast material. It

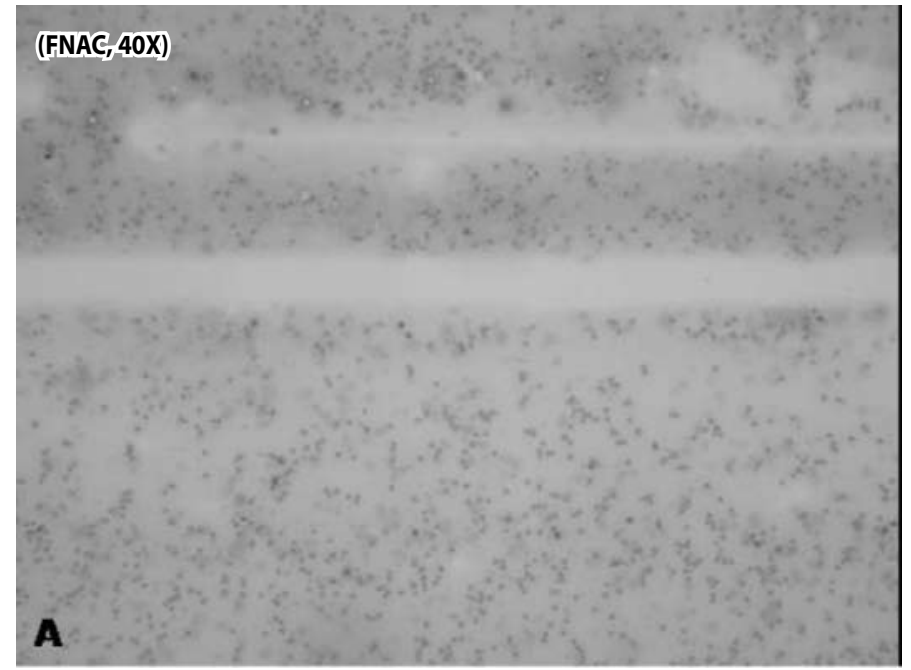

(FNAC, 400X)

B

Figure 2. Fine-Needle Aspiration Cytology (FNAC) of the supra-auricular nodular lesion 2.A Scanning view (40x) showing adequate hypocellular smears

2.B High-power magnification (400x) shows mainly lymphocytes against background of many red blood cells. No atypical cells seen.

is also helpful in tumor origin and extension, therefore providing valid diagnostic support for further management and surgery. ${ }^{9}$ MRI features may help delineate the extent of the lesion, but the signal characteristics generally are nonspecific. In our case, the HRCT showed a poorly enhancing mass with well demarcated border, intact temporalis fascia and delimited fat pad without bony erosion or soft tissue infiltration - making the consideration of a high-grade malignancy least likely. MRI was not necessary because the surrounding structures were already delineated with the HRCT. However, MRI may be necessary in evaluating soft tissue structures in the vascular type of nodular fasciitis. ${ }^{5}$

With the acute onset and rapid growth of the nodular mass, FNAC is necessary to rule out a malignant etiology. FNAC of nodular fascitis 

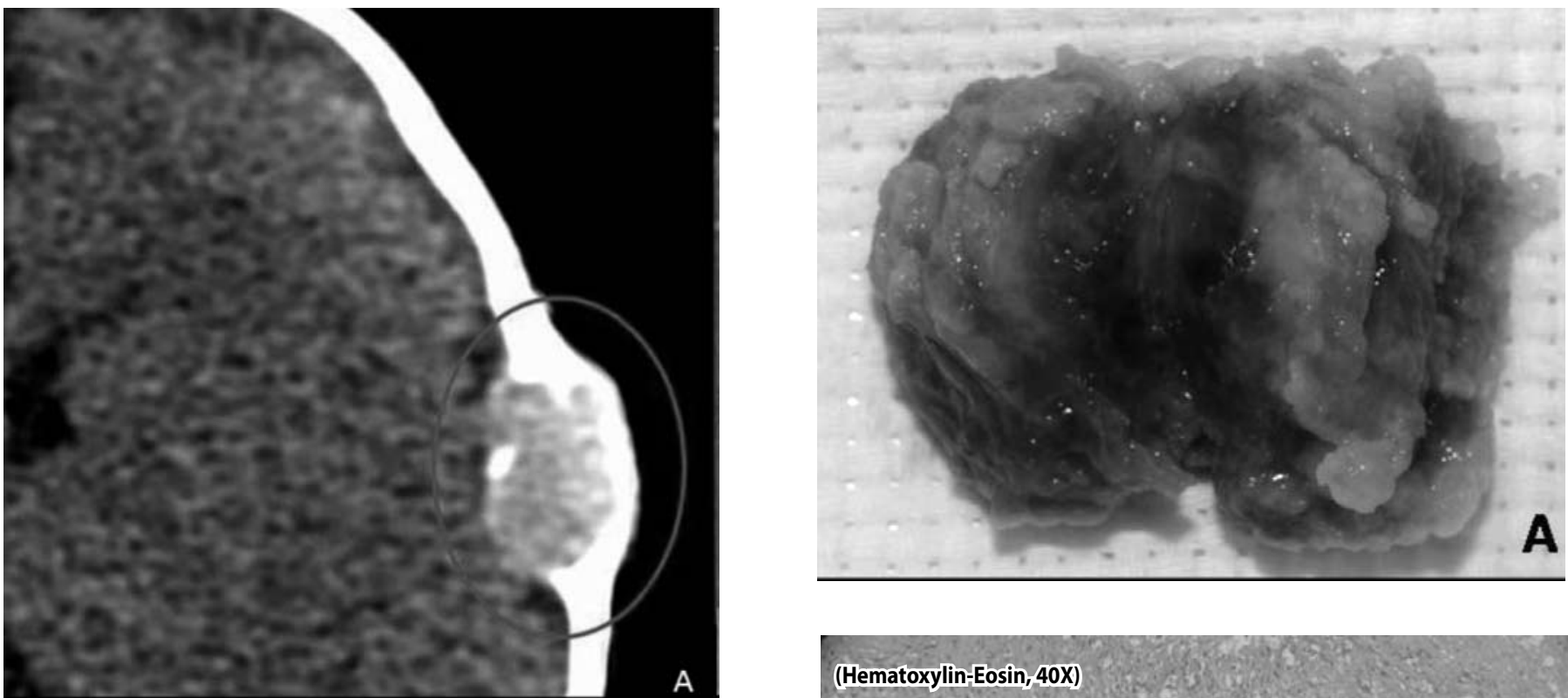

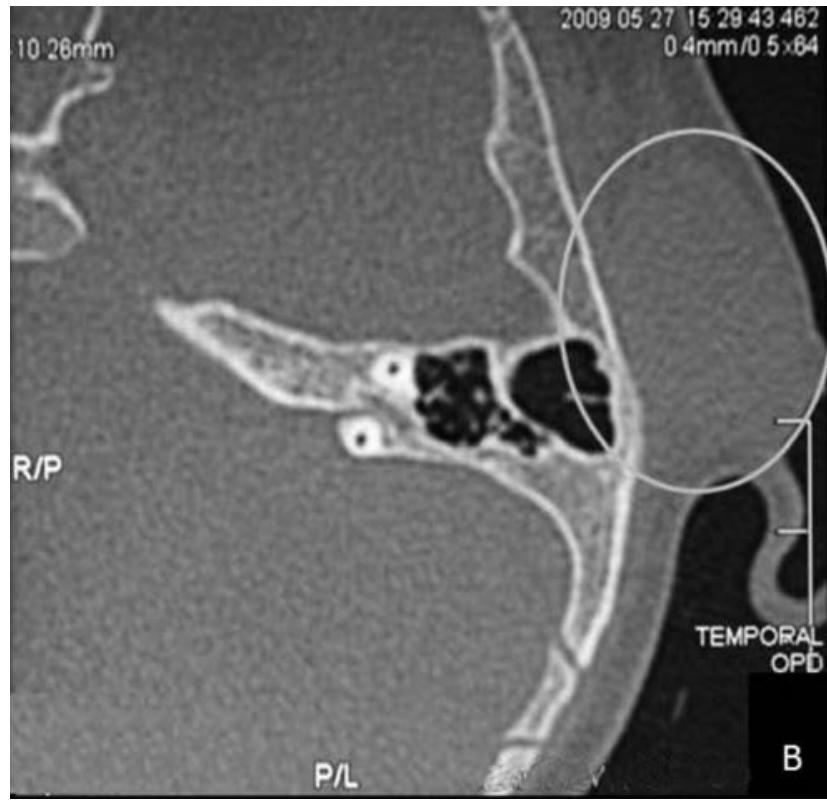

Figure 3. Axial CT image of a case of cranial fasciitis, initially diagnosed as spindle cell carcinoma (A) and the patient's axial CT imaging in which sarcoma was initially considered (B).

3.B Axial view showing a soft tissue mass with destruction of the inner and outer cranial tables (source: Keyserling HF, Castillo M, Smith JK. Cranial fasciitis of childhood. AJNR Am J Neuroradiol, 2003 Aug; 24(7): 1465-1467. Reproduced with permission from AJNR available from http://www.4shared.com/document/ nWb2z1Yq/Fernando.htm

3.B Axial view of the patient's temporal bone showing a faintly-enhancing soft tissue density overlying the temporalis muscle with well-demarcated fatty border without evidence of bony extension or erosion. The temporal bone at the petrous apex showed normal middle and inner ear structures.

demonstrates features of benign appearing spindle cells, collagen and myxoid materials.,11 Differential diagnosis of a rapidly progressive mass in the patient's age group would include benign fibrous histiocytoma, pleomorphic lipoma and hemangioma. ${ }^{9}$ Also, aggressive fibromatosis,
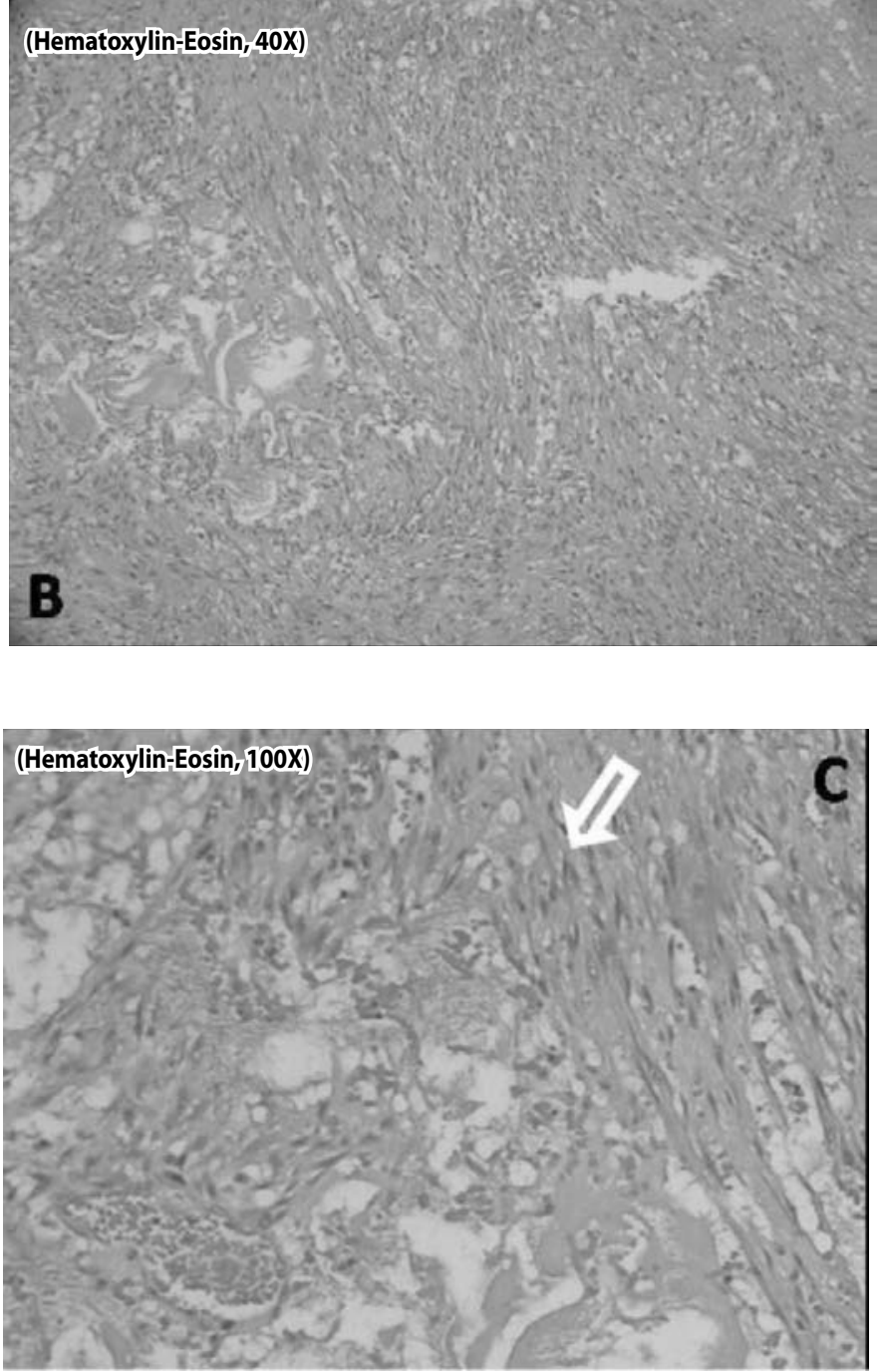


\section{CASE REPORTS}

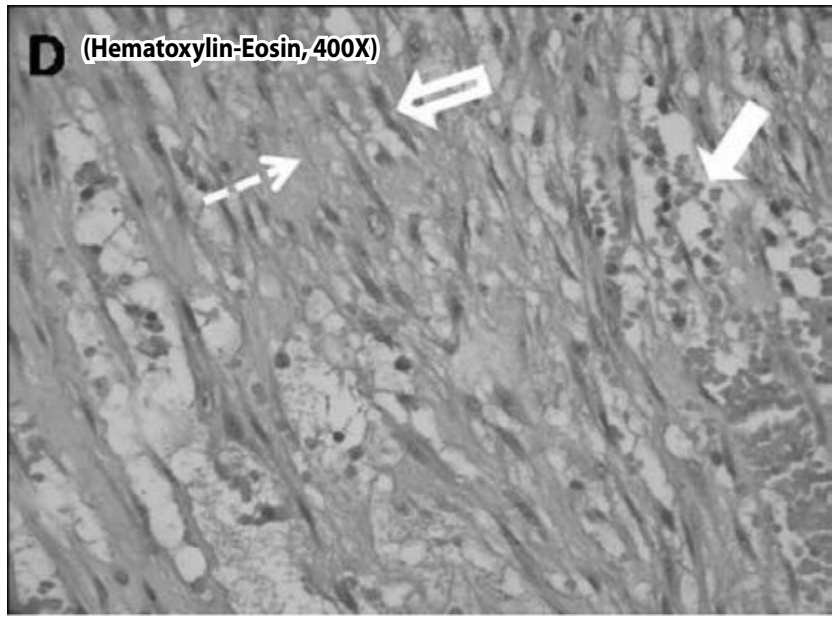

Figure 4. Gross and histopathologic picture of the supra-auricular nodular lesion after complete excision stained with hematoxylin-eosin.

4.A Relatively well-circumscribed, unencapsulated nodular mass measuring $2.8 \mathrm{~cm}$ in its widest diameter and subcutaneously located. The cut surface showed a relative amount of fibrous tissue with firm rubbery consistency without muscular or bony tissue.

4.B Note the vast array of patterns with some inflammatory cells and an accelerated mitotic index (40x magnification)

4.C Note the fibroblasts (arrow) and myofibroblasts arranged in short irregular bundles and usually accompanied by dense reticulin fibrosis (100x magnification).

4.D Stroma rich in collagen and/or myxoid ground substance (broken arrow) with fibroblasts uniform and spindle-shaped in appearance (unfilled arrow). Extravasated erythrocytes (bold arrow) were also noted with micro-hemorrhages (400x magnification).

a rare condition marked by the presence of multiple benign slow growing tumors known as desmoid tumors must also be ruled out through detailed history and physical examination. Although desmoid tumors are benign, they may appear anywhere causing multiple organ dysfunction. ${ }^{5,6}$ Malignant considerations on the other hand are sarcomas of the pleomorphic type which include osteosarcoma, rhabdosarcoma, leiomyosarcoma and osteoclastoma, all of which have distinct radiologic and pathologic features of invasiveness of surrounding structures. ${ }^{1,6,8}$

Diagnosis of nodular fasciitis is often challenging because it may be confused with various malignant tumors due to its aggressive clinical behavior and histo-cytologic features. Clinically, nodular fasciitis presents as a painless, fast-growing mass that commonly occurs in an extremity. However, $20 \%$ occur in the head and neck region and 10\% of patients recall antecedent trauma (Table 2).,10,11 A 2001 study by Thompson, et al. ${ }^{12}$ of patients diagnosed with auricular nodular fasciitis noted that:

Most nodular fasciitis are dermal (56\%) and subcutaneous (22\%) usually measuring $1.9 \mathrm{~cm}$ in widest diameter. Lesions are usually circumscribed with spindle-shaped to stellate myofibroblasts arranged in a storiform growth pattern, juxtaposed to hypocellular myxoid tissueculture-like areas with extravasation of erythrocytes. Also a common histologic finding are dense, keloid-like collagen and giant cells in the absence of atypical forms and does not exhibit stromal invasion, a classic

\section{histologic sign of tumor invasiveness.}

There are few reports of spontaneous regression of nodular fasciitis making a complete excision with minimal inclusion of surrounding subcutaneous tissue the management of choice. ${ }^{13}$ In some cases where information is necessary to avoid over treatment and resection, immunohistochemical staining may be of value as myofibroblasts are reactive with vimentin, actins, and $\mathrm{CD} 688^{8,14}$ The recurrence rate of nodular fasciitis is low and generally ranges from $0-0.004 \% .{ }^{14}$ Local recurrence was noted at $9.3 \%$ in 50 cases of nodular fasciitis of the external ear which was attributed to difficulties in obtaining clear surgical margins for the said region. ${ }^{12}$

There are hardly any locally reported cases on nodular fasciitis which could be due to failed recognition, misdiagnosed surgical excisions or lack of patient follow-up as in the case of medical missions. The location should always be correlated with the other clinical findings as misdiagnosis could lead to a wider surgical resection and higher morbidity. ${ }^{1,6,10}$ Histopathologic recognition with FNAC requires familiarization with its vast array of histologic appearances to avoid expensive and unnecessary immunohistochemistry stains as complete surgical excision of the mass already suffices. ${ }^{10,14}$ Indeed, appropriate management of nodular fasciitis requires deeper familiarity with the condition so as to minimize excessive, expensive and unnecessary procedures, and prevent unwanted morbidities.

\section{ACKNOWLEDGMENT}

The authors thank Janelyn Alexis L. Dy, M.D. and Janet L. Dy, M.D., resident and consultant respectively of the Department of Pathology of the University of the East Ramon Magsaysay Memoria Medical Center, Inc. for their invaluable help with the pathologic interpretation and analysis of this case.

\section{REFERENCES}

1. Handa Y, Asai T, Tomita Y. Nodular fasciitis of the forehead in a pediatric patient. Dermatol Surg 2003 Aug 29(8):867-868

2. Rosenberg A. Bones, Joints and Soft Tissue Tumors. In: Cotran R, Kumar V, Collins T. editors. Robbins Pathologic Basis of Disease, $6^{\text {th }}$ ed. Philadelphia: W. B. Saunders Co.1999. p. 1259 $-1267$.

3. Konwaler BE, Keasbey L, Kaplan L. Subcutaneous pseudosarcomatous fibromatosis (fasciitis). Am J Clin Pathol. 1955 Mar; 25(3):241-252.

4. Bernstein $\mathrm{KE}$, Lattes R. Nodular (pseudosarcomatous) fasciitis, a nonrecurrent lesion: clinicopathologic study of 134 cases, Cancer. 1982 Apr 15; 49(8):1668-1678.

5. Koenigsberg RA, Faro S, Chen X, Marlowe F. Nodular fasciitis as a vascular neck mass. AJNR Am J Neuroradiol. 1996 Mar; 17(3):567-569.

6. Keyserling HF, Castillo M, Smith JK. Cranial fasciitis of childhood. AJNR Am J Neuroradiol. 2003 Aug; 24(7): 1465-1467.

7. Mardi K, Sharma J, Kaur H. Nodular fasciitis of the hand - a potential diagnostic pitfall in fine needle aspiration cytology. J Cytol. 2007 Oct - Dec; 24 (4):197-198.

8. Kolo KO, Karhousen J, Von Baer A, Land grebek, Craciun M, Nussle K. Radiologic - pathologic conference Nodular Fascitis, Roentgen Praxis, 1997 Aug; 50(8): 229-232.

9. Vyas T, Bullock MJ, Hart RD, Trites JR, Taylor SM. Nodular fasciitis of the zygoma: A case report. Can J Plast Surg. 2008 Winter; 16(4): 241-243.

10. Cartwright LE, Steinman HK. Rapidly growing, asymptomatic subcutaneous nodules. Arch Dermatol. 1988 Oct; 124(10):1559-1560.

11. Stanley MW, Skoog L, Tani EM, Horwitz CA. Nodular Fascitis: spontaneous resolution following diagnosis by fine-needle aspiration. Diagn Cytopathol. 1993 May; 9(3): 322-324.

12. Thompson LD, Fanburg-Smith JC, Wenig BM. Nodular fasciitis of the external ear region: a clinicopathologic study of 50 cases. Ann Diagn Pathol. 2001 Aug; 5(4):191-198.

13. Hüter EN, Lee CCR, Sherry RM, Udey MC. Spontaneous regression and recurrence in a case of nodular fasciitis. Acta Derm Venereol. 2009 Jul; 89(4):438-439.

14. Shimizu S, Hashimoto H, Enjoji M. Nodular fasciitis: an analysis of 250 patients. Pathology. 1984 Apr; 16(2): 161-166. 